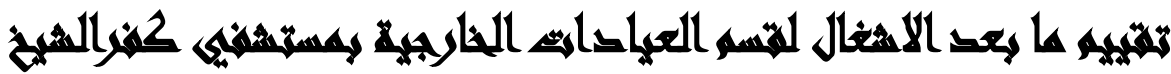

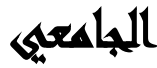

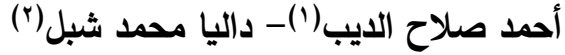

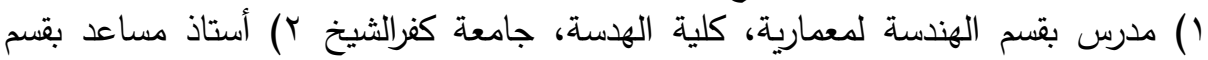

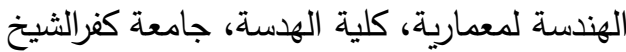

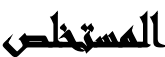

طرق تقييم ما بعد الاشغال لمباني الرعاية الصحية متعددة منها ما يعتمد علي قياس

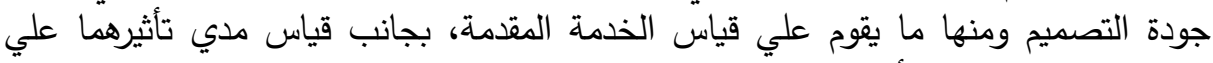

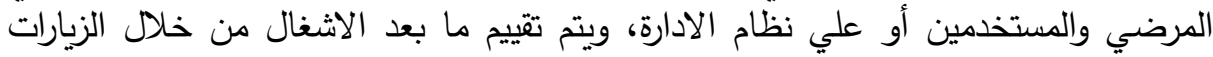

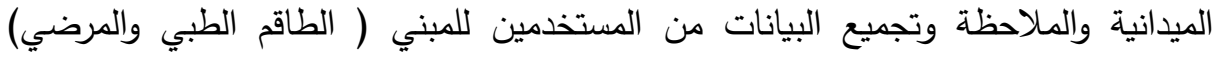

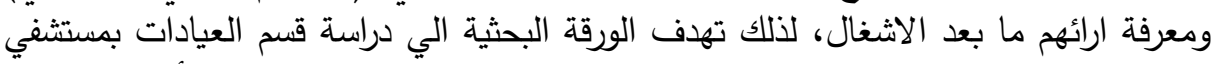

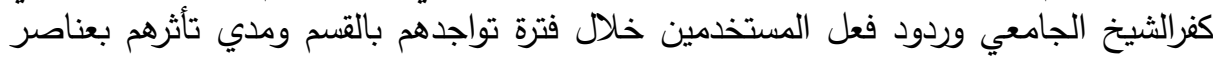

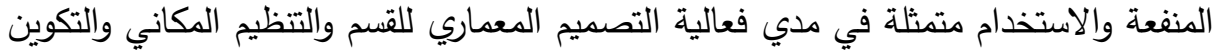

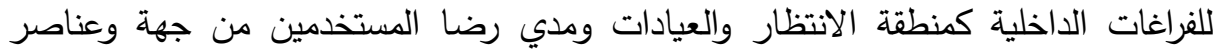

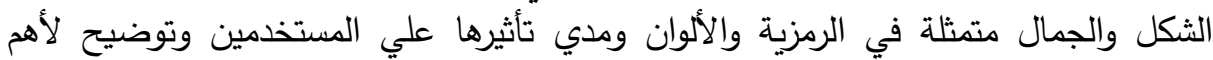

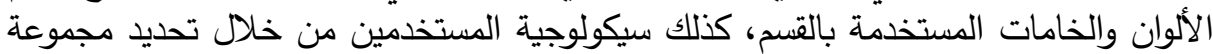

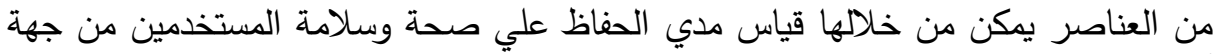

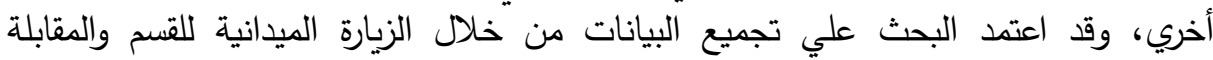

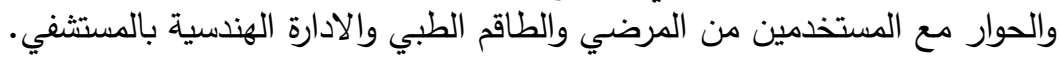

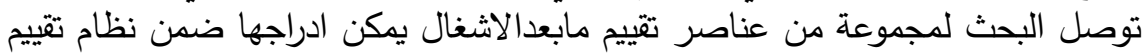
عام خاص بالمستثفي ومنها أمكن تقديم مقترح ثلاثي الأبعاد لتعديل قسم العيادات بمستثنفي

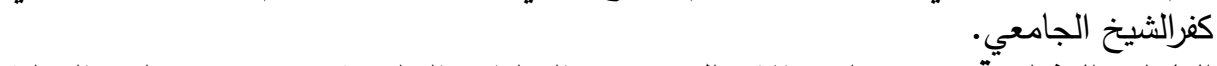
الكلمات المفتاحيّة: تقييم مابعد الاشغال - قسم العيادات الخارجية - تصميم مباني الرعاية

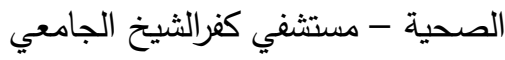

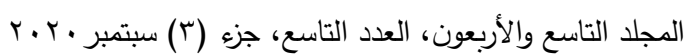

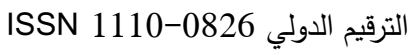




\section{Max}

ينظر الي قطاعات عديدة من المباني علي انها لا تستطيع التطوير والتجديد من نفسها بمرور الوقت علي الرغم من أنه يمكن حل المشاكل بالنظر الي المشاريع السابقة وتفادي الأخطاء التي ظهرت بها - كما هو الحال في مجال الصناعة - لذلك تتناول الورقة البحثية تقييم ما بعد الاشغال للمباني وخاصة قسم العيادات الخارجية بمستشفي كفرالثيخ الجامعي للوقوف علي وظيفة المبني الفعلية والأهداف التصميمية التي صُمم علي أساسها المبني. يلعب تقييم ما بعد الاشغال دورا هام في احداث تغييرات كبيرة في قطاع البناء وذلك من ونه خلال اظهار مدي ملائمة المبني للغرض الذي انثأ من اجله من خلال تلبية العديد من الأحتياجات المتزايدة والسريعه سواء على المستوى الاجتماعى أو الثقافى أو البيئى علي المدي

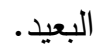

عملية تقييم ما بعد الاشغال يوجد لها الكثير من المفاهيم والتي تثير الي معالجة

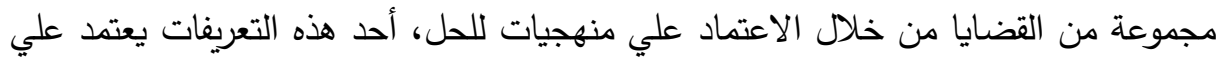
تحليل عملية تقييم ما بعد الاشغال الي جزئين (Hay 2017): - التحقق من مدي تطبيق الجودة ومعايير التصميم والبناء ( تصميم المبني - استهلاك

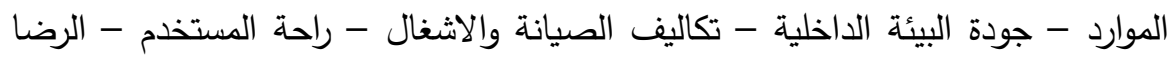

$$
\text { والنتائج أو المخرجات). }
$$

- التعلم المستمر ونشر ثقافة تقييم الاشغال لتصميم مباني مستقبلية مناسبة. لذلك فقد ازداد استخدام تقييم ما بعد الاشغال لدي المعماريين في السنوات الأخيرة نتيجة لتزايد الوعي بالأبحاث وثيقة الصلة، ولزياده دور عملية التقييم وفاعليتها وتأثيرها فى دوره حياه المبنى " Life Cycle "منذ بداية التصميم فان مؤسسات الرعاية الصحية تهتم بردود الفعل

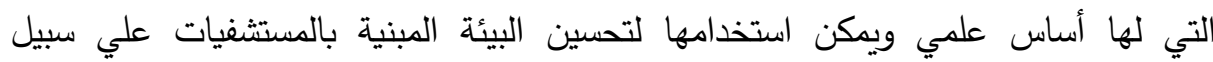

$$
\text { المثال(استخدام المواد - التصميم المعماري - وصول ضوي التهي النهار - التوجيه). }
$$




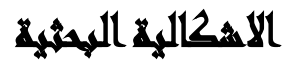

تتضح الاشكالية البحثية في عدم وجود عناصر واضحة لنظام تقييم ما بعد الاشغال والتي يكون لها دور كبير في نجاح العديد من الأهداف المطلوبة لما بعد الاشغال، ففي الوقت الراهن، الأبحاث والدراسات المتاحة حول تقييم بعد الاشغال لقسم العيادات الخارجية تعتمد

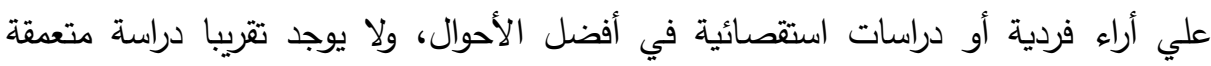

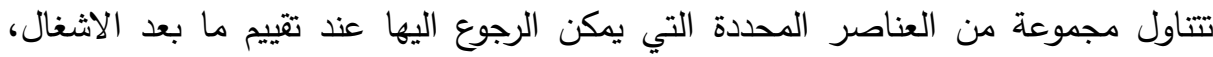

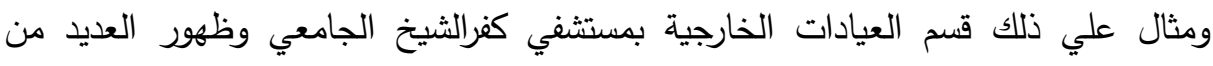
مشاكل ما بعد الاشغال كالوظيفة والتتظيم المكاني ورضا المستخدمين والألوان المستخدمة

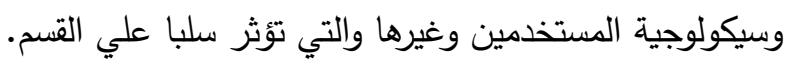

\section{Andlition}

يتلخص الهدف الرئيسي للبحث في الوصول لمجموعة من العناصر التي يمكن الاعتماد

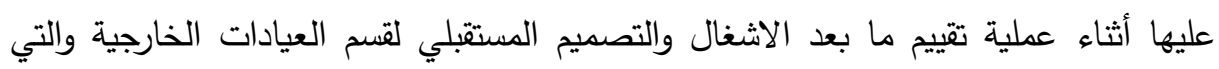
بدورها تساعدنا في الوقوف علي الفروقات الموجودة في التصميم والاشغال، ودراسة كيفية استخدام البيئة المبنية ومدي تأثيرها على القرارات التصميمية، ومن ثم تقديم مقترح تطوير العيادات الخارجية بمستثفي كفرالثيخ الجامعي طبقا لعناصر تقييم ما بعد الاشغال.

\section{نطالة المهيث}

دراسة مفهوم تقييم ما بعد الاشغال للمباني وأهم مستوياته والأهداف المرجوة من التقييم

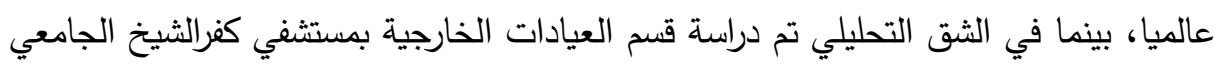
متمثل في مجموعة من المحددات كالوظيفة والفعالية التصميمية والتتظيم والتكوين المكاني

$$
\begin{aligned}
& \text { r. r. . المجلد التاسع والأربعون، العدد التاسع، جزء (r) سبتمبر }
\end{aligned}
$$

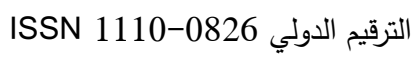


ورضا المستخدمين بالاضافة الي الرمزية والألوان وسيكولوجية المستخدمين والصحة والسلامة العامة للمستخدمين.

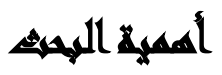

ظهرت أنظمة تثييم ما بعد الاشغال في البداية كطريقة لتقييم شكاوي المستخدمين حول جودة التصميم ومع مرور الوقت انتشرت تطبيقات تقييم ما بعد الاشغال لتتعدي من كونها

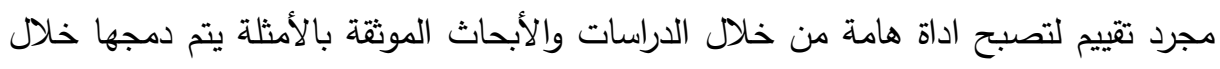

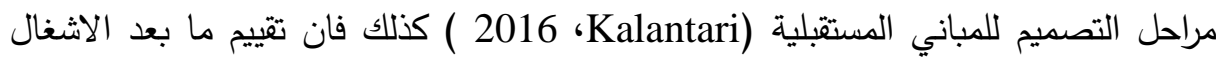
لمباني الرعاية الصحية محدود حيث يتم من خلال الباحثين سواء في اجراء دراسات علي

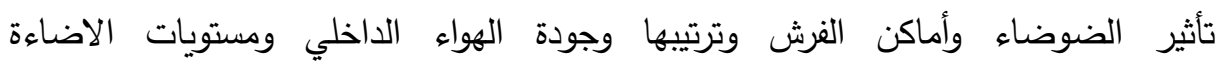
والخصوصية، ومع ذلك عدد قليل من الدراسات الذي يتاول تقييم ما بعد اشغال العيادات

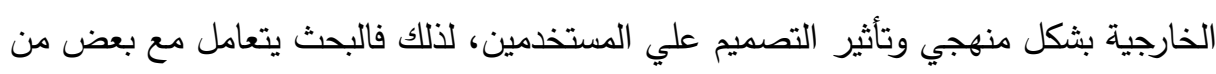

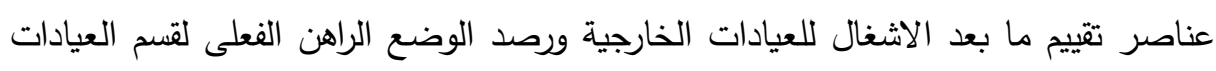

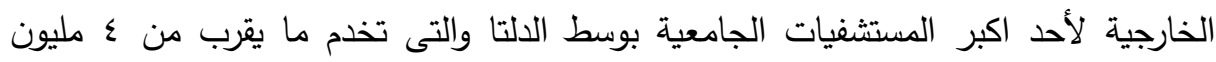
نسمة.

\section{And}

أ- المنهج التحليلي: تحليل ووصف لتقييم ما بعد الاثغال ومعرفة مستوياته وطرقه المختلفة وأهميته والتي ساعد في ايجاد بعض العناصر تم الاعتماد عليها في المراحل

ب- المنهج الاستقرائي: الاعتماد علي المقابلات والدراسات الاستقصائية لجمع البيانات حول رؤية المستخدمين وتعليقاتهم " التغذية الراجعة" حول البيئة المبنية، تم الاعتماد علي

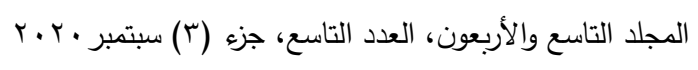

الترقيم الدولي 0826-1110 الأبعن، 


$$
\begin{aligned}
& \text { مجلة العلوم البيئية } \\
& \text { معهد الدراسات والبحوث البيئية - جامعة عين شمس } \\
& \text { أحمد صلاح الديب وآخرون }
\end{aligned}
$$

أكثر من مدخل لدراسة تقييم ما بعد الاشغال وذلك بدمج العناصر الكمية والكيفية معا، شملت المكونات الكيفية التركيز علي المقابلات مع كبار الاطباء وكذلك مع المصممين المعماريين، بينما المكون الكمي شمل اجراء مقابلات مع عدد كبير من هيئة المستثفي كئي

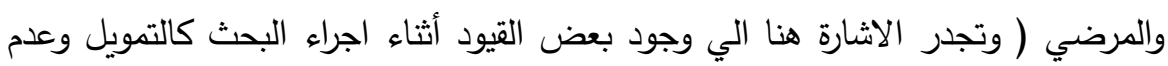

$$
\text { الوصول الي بعض المصادر الهامة كسجلات المرضي). }
$$

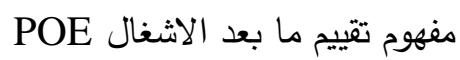

يعتبر نظام تقييم ما بعد الاشغال من أكثر الأنظمة انتشارا للمباني، ويشير مصطيح تقييم ما بعد الاشغال الي مدي حقيقة استخدام المبني وتأدية الوظيفة المقام من أجلها أثناء عملية التقييم(Preiser، 2005)، ويعرف علي أنه منهجية محددة تهتم بالمساحات والمواصفات وما اذا كانت تفي باحتياجات المستخدمين أم لا، كما أنها تركز علي الأبحاث

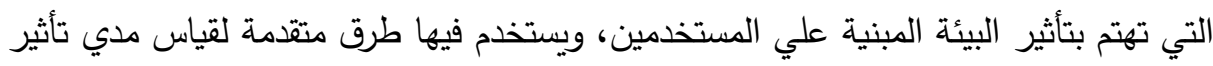
التداخلات المختلفة للتصميم علي نتائج ومخرجات المستخدمين كرضا المستخدمين والسلامة والصحة ( Watkins 2012 ).

ويعتبر نظام التقييم نوع من أنواع الدراسات الميدانية والتي تمثل تحديا أمام الباحثين حيث ان متغيرات الدراسة يصعب التحكم فيها وهذا المستوي من التحكم ليس من السهل تحقيقه. تم استخدام تقييم ما بعد الاشغال للمباني في اواخر الستينيات في الولايات المتحدة

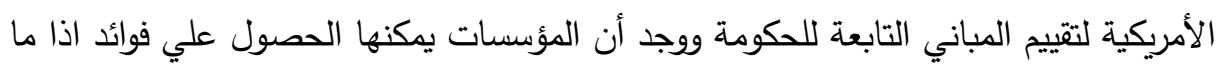
طبقت هذه الأنظمة( Preiser 2016) بصورة عامة نجد أن كل مبني وبالتالي كل قصم يختلف عن المباني الأخري في المشاكل الموجودة به ولكن يمكن أن تكون هناك مشكلة عامة تتطلب حلا محددا ( مثال:

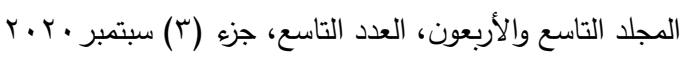

$$
\begin{aligned}
& \text { الترقيم الدولي 0826-1110 }
\end{aligned}
$$




$$
\begin{aligned}
& \text { مجلة العلوم البيئية } \\
& \text { معهد الدراسات والبحوث البيئية - جامعة عين شمس له } \\
& \text { أحمد صلاح الديب وآخرون }
\end{aligned}
$$

المسافات الطويلة التي يقطعها الفريق المعالج)، ومع التركيز علي مثل هذه الأبحاث يمكننا تصميم شبكة بحثية علمية علي نطاق عالمي بأقل تكاليف وجها. نظرة عامة علي طرق التقييم ما بعد الاشغال: يوجد أكثر من ـ10 نموذج لتقييم ما

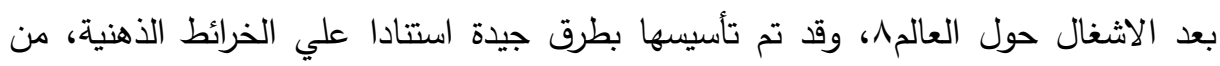
ضمن تلك النماذج تقييم الزهرة Evaluation Focus Flower شكل (1) والتي تقدم نظرة عامة علي طرق التقييم المتاحة وذلك من خلال التركيز علي الأماكن التي يمكن اجراء تقييم

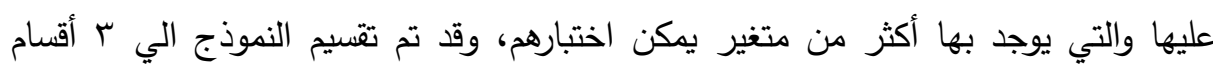

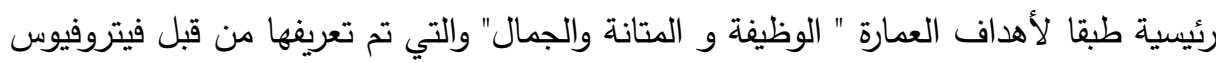

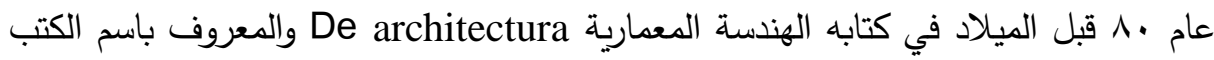
العشر في العمارة(Munter 2013).

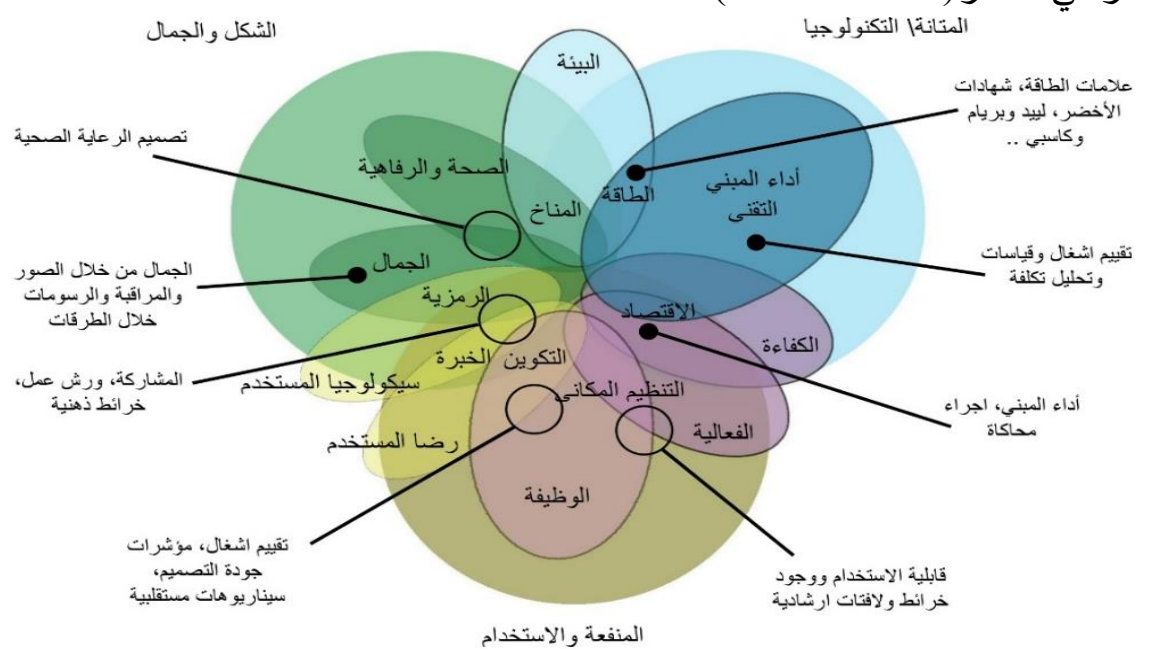

شكل(1) نموذج تقييم الزهرة Evaluation Focus Flower يوضح بعض الأماكن التي يمكن اجراء التقييم عندها بناء علي اماكن التركيز ( Evaluation methods

.(for hospital facilities 2013

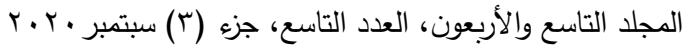

$$
\begin{aligned}
& \text { الترقيم الدولي 0826-1110 الارعون، }
\end{aligned}
$$




$$
\begin{aligned}
& \text { مجلة العلوم البيئية } \\
& \text { معهد الدراسات والبحوث البيئية - جامعة عين شمس لكس } \\
& \text { أحمد صلاح الديب وآخرون }
\end{aligned}
$$

مستويات تقييم ما بعد الاشغال

يوجد r مستويات لنظام تقييم ما بعد الاشغال وهي كالتالي: ارشادي: وهو عملية تقييم سريعة تشمل مقابلات مع كبار الموظفين وعقد اجتماعات مع المستخدمين والمرور خلال المبني، وتكون النتائج نظرة عامة سريعة علي الجوانب الايجابية والسلبية لأداء المبني. تحقيق أعلي تقييم: وذلك باجراء مقابلات واستبيانات وتسجيلات فوتوغرافية واجراء قياسات فعلية ومقارناتها مع الأهداف، وتكون النتائج أكثر تعمقا وافادة للمؤسسة. تشخيصي: اجراء دراسة تقييم طويلة لأداء المبني بأسلوب بحثي (Munter، 2017).

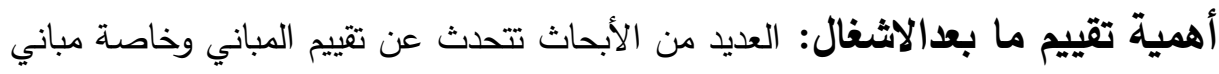
الرعاية الصحية كذلك المنظمات والهيئات مثل المنظمة البحثية للتصميم البيئي والتي قامت باعداد عدد من المؤتمرات في هذا المجال، ومركز الصحة والثفاء لماتهيك

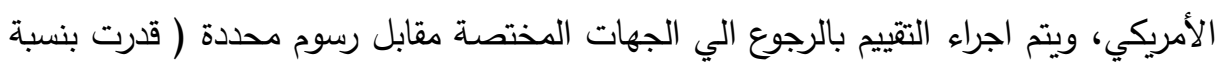

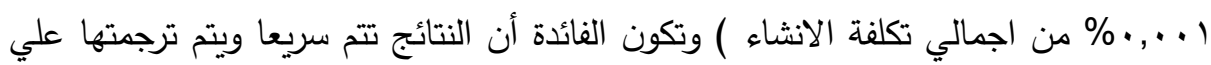
أرض الواقع Watkins ، من (2012).

فعملية تقييم ما بعد الاشغال والتغذية الراجعة مكونان رئيسيان لتحسين البيئة المبنية وخاصة بيئة الرعاية الصحية ولها الكثير من المميزات كما في جدول (1)، كذلك فان ميزات

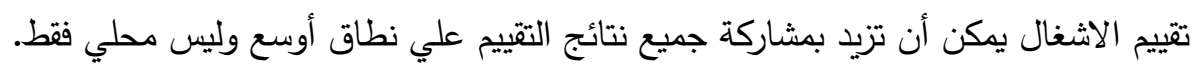

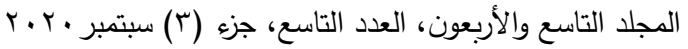

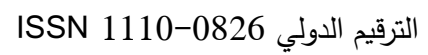




$$
\begin{aligned}
& \text { مجلة العلوم البيئية } \\
& \text { معهد الدراسات والبحوث البيئية - جامعة عين شمس له } \\
& \text { أحمد صلاح الديب وآخرون }
\end{aligned}
$$

\begin{tabular}{|c|c|}
\hline 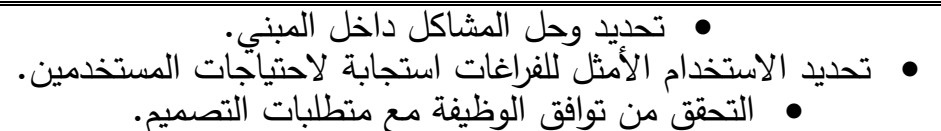 & المدي القصيز : ميزي : \\
\hline 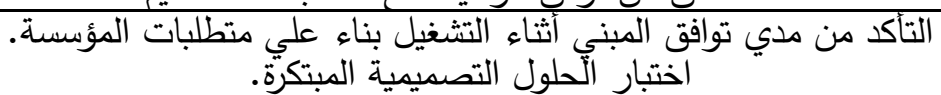 & المدي المتوسيط: علي: \\
\hline 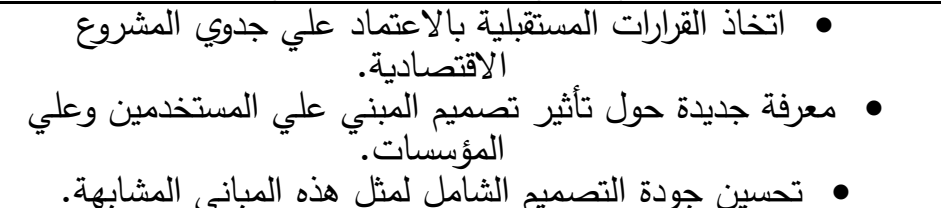 & المديري البعيذي: \\
\hline
\end{tabular}

جدول(1): مميزات تقييم ما بعد الاشغال (The Centre for Health design، 2015).

لماذا عملية تقييم ما بعد الاشغال: يوجد العديد من الأسباب لاجراء عملية تقييم ما بعد

$$
\text { الاشغال وقد تم تقسيمهم الي ب مجموعات: }
$$

المعرفة: معرفة المكان وما وصل اليه وما هي نظريات التطوير المتاحة. السيطرة والتحكم: معرفة تجارب الاخرين مع المكان وجمع المعلومات منهم. معلومات مهنية متخصصة: معرفة تقييمات الخبراء ومناقشتها (Munter، 2013). ومن خلال شكل (r) يتضح الأسباب المختلفة لتقييم المباني، حيث يوجد علي المحور الأفقي شكل المبني وتصميمه ومستوي الابداع به، بينما المحور الرأسي يوضح حالة المبني

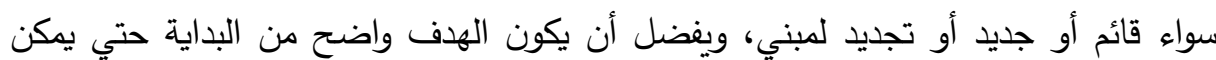
مقارنة الأهداف مع النتائج. 


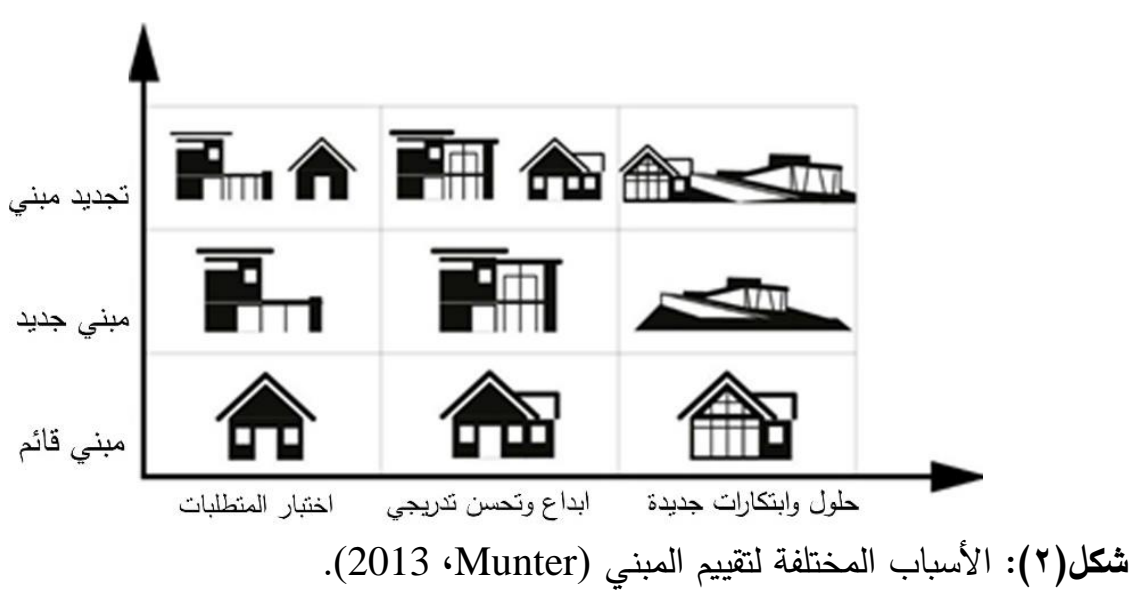

قسم العيادات الخارجية - المستشفي الجامعي - جامعة كفرالشيخ: يتناول البحث في الجزء التالي منه دراسة قسم العيادات الخارجية بمستثفي كفر الثيخ الجامعي بمصر للمساعدة في البدء في ايجاد عناصر مساعدة لاجراء تقييم ما بعد الاشغال له، وذلك لكأل لكونه يواجه تحديات تشغيلية متعددة علي الرغم من حداثة انثائه وباعتباره أحد أهم الأقسام الموجودة بالمستثفي حيث يتردد عليه أكثر من . .0 مريض يوميا. تم تخصيص منطقة طبية داخل الحرم الجامعي للجامعة ( تقع جامعة كفرالثيخ عند المدخل الجنوبي لمدينة كفرالثيخ) والتي تحتوي علي مستثفي وكلية الطب البشري والعلاج الطبيعي والأسنان والصيدلة. قسم العيادات الخارجية بالدور الأرضي بالمستشفي شكل(r) لله مدخل من الجهة الجنوبية الثرقية وباقي العيادات في الجهة الجنوبية الغربية ويتم الاتصال بينهم من قسم الاشعة أو من منطقة الغازات ومتصل بعناصر المستثفي بالممرات جدول (؟)، ويحتوي القسم علي عيادات متخصصة (عظام - رمد - أنف- قلب - مسالك - نسا - أوعية - جراحة الصدر - تجميل - فيروسات كبدية - نفسية وعصبية - سمعية - أطفال - مخ وأعصاب -

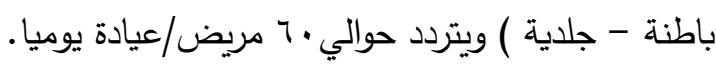

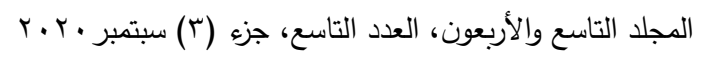




$$
\begin{aligned}
& \text { مجلة العلوم البيئية } \\
& \text { معهد الدراسات والبحوث البيئية - جامعة عين شمس لئه } \\
& \text { أحمد صلاح الديب وآخرون }
\end{aligned}
$$

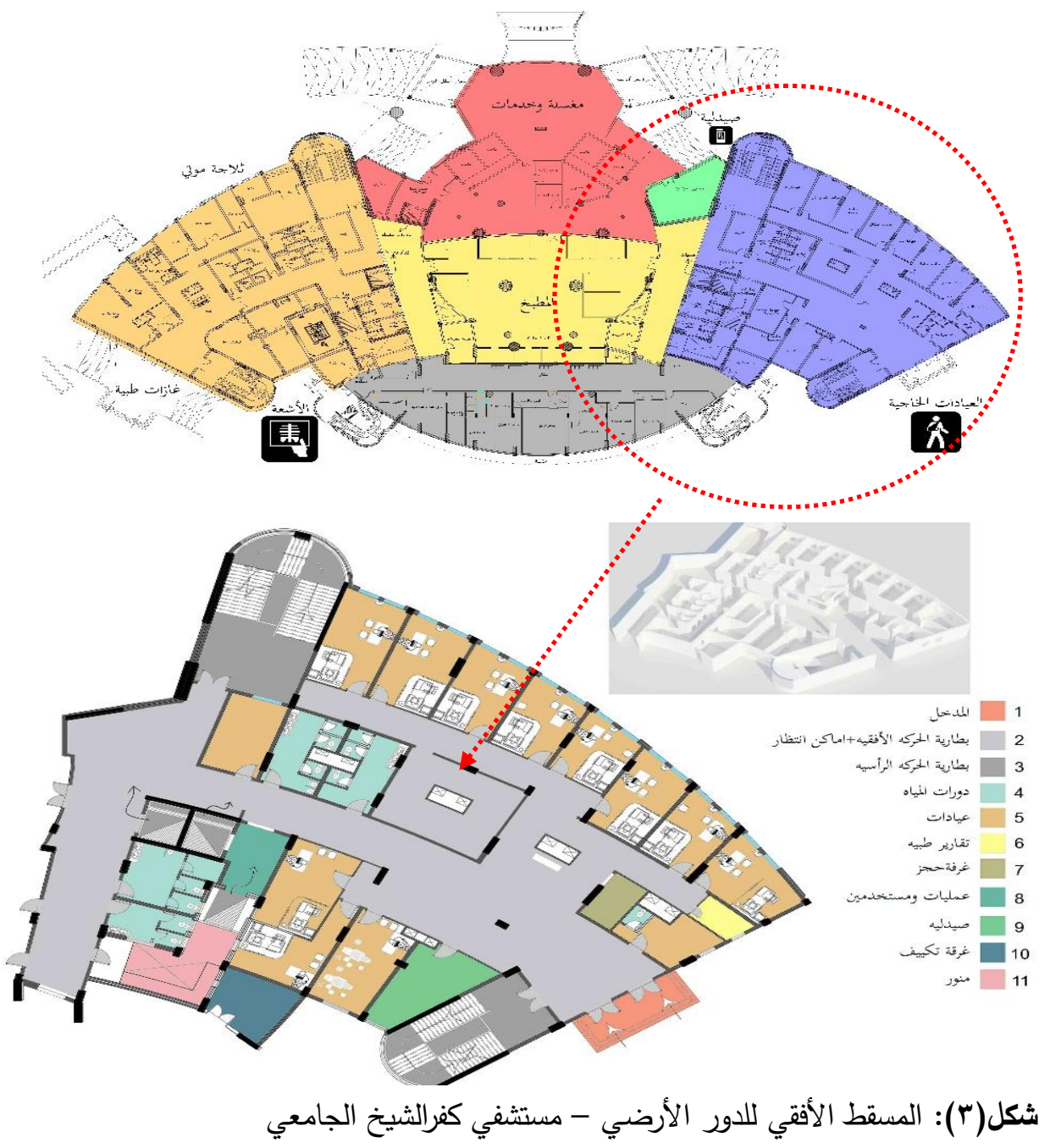

40

المجلد التاسع والأربعون، العدد التاسع، جزء (r) سبتمبر • r. F

الترقيم الدولي 0826-1110 1SSN 


$$
\begin{aligned}
& \text { مجلة العلوم البيئية } \\
& \text { معهد الدراسات والبحوث البيئية - جامعة عين شمس } \\
& \text { أحمد صلاح الديب وآخرون }
\end{aligned}
$$

\begin{tabular}{|c|c|c|c|c|c|c|}
\hline التصميميية & المؤسافة & الأطباء & نوع الخدمة & الوصوق & العنوان & المشروع \\
\hline 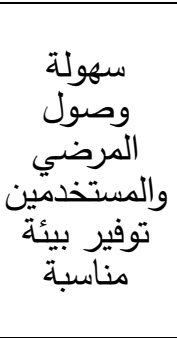 & 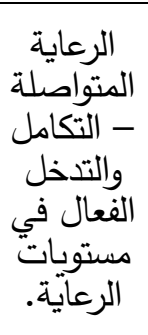 & 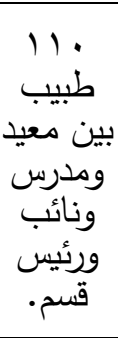 & 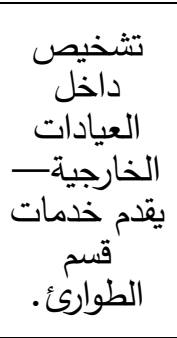 & كفرالثينة & 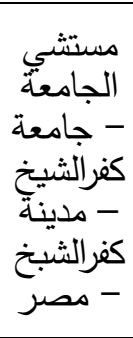 & 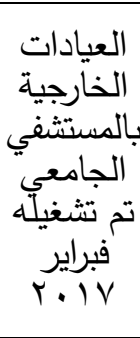 \\
\hline
\end{tabular}

العناصر المؤثرة علي تقييم ما بعد الاشغال بقسم العيادات الخارجية مستشفي كفر الثيخ الجامعي: يوجد عدد من العناصر التي تؤثر علي تتييم ما بعد

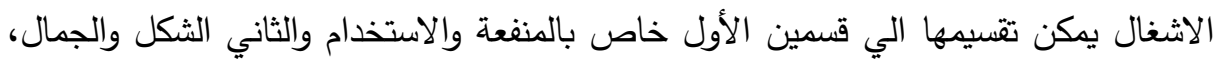

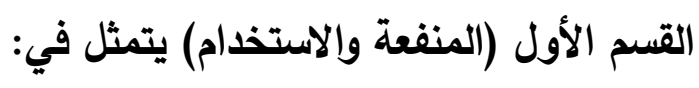

ا. الوظيفة والفعالية: التصميم المعماري له دور كبير في تحقيق أفضل وظيفة وبالتالي أكثر

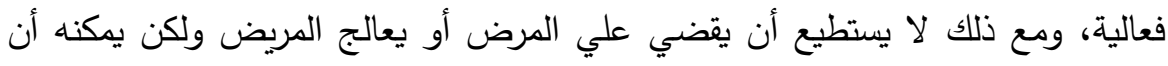

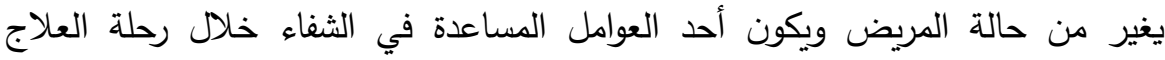

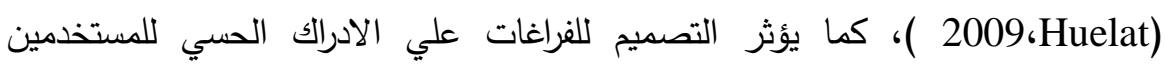
وضمان استمرار العاملين في عملهم وبالتالي الحفاظ علي جودة وكفاءة النتائج، ويؤثر التراتر علي ظروف التعامل بين المرضي وزويهم وأعضاء الفريق المعالج، يتم اختباره من خلال

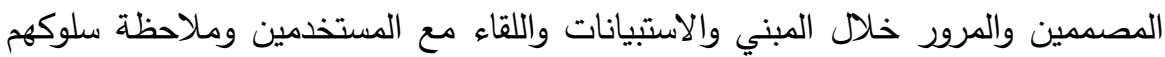
والحالة المزاجية لهم وتحليل الفراغات ومساحاتها (Haron 2011).

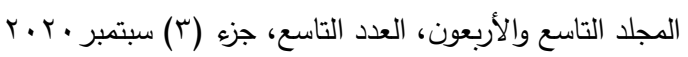

$$
\begin{aligned}
& \text { الترقيم الدولي 0826-1110 }
\end{aligned}
$$


وبدراسة التصميم المعماري للمستثفي والزيارات الميدانية تبين الاتي جدول (r): جدول(ץ): الوظيفة والفعالية لقسم العيادات الخارجية لمستثفي كفرالثيخ الجامعي.

\begin{tabular}{|c|c|}
\hline 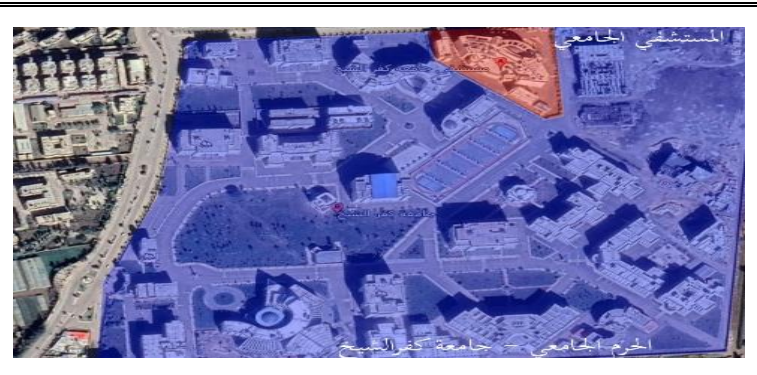 & 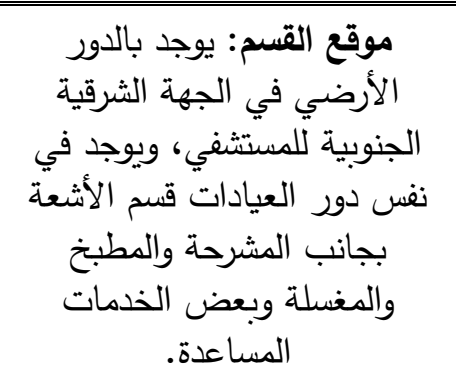 \\
\hline & 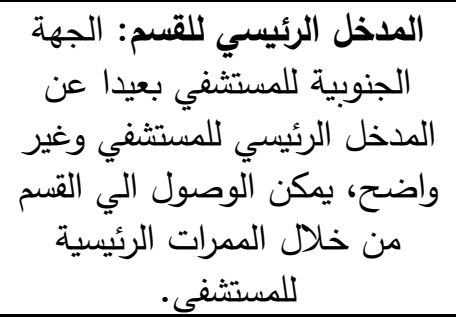 \\
\hline تتظار & 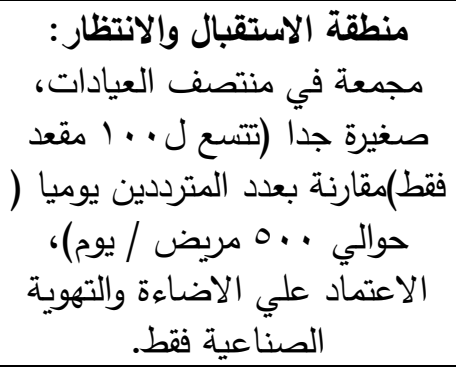 \\
\hline 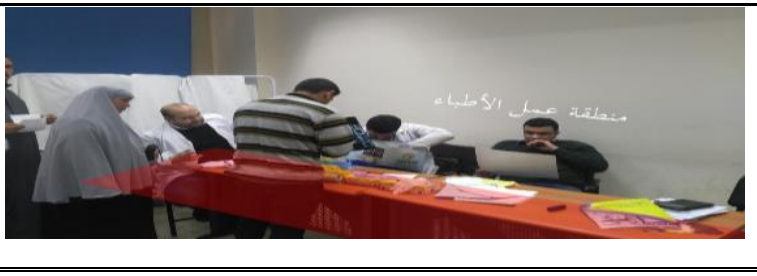 & 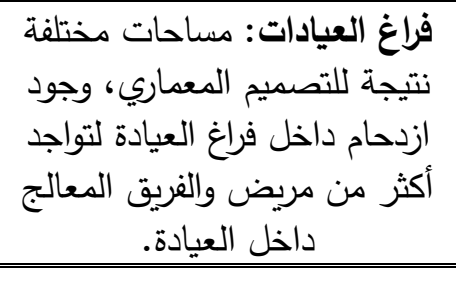 \\
\hline
\end{tabular}




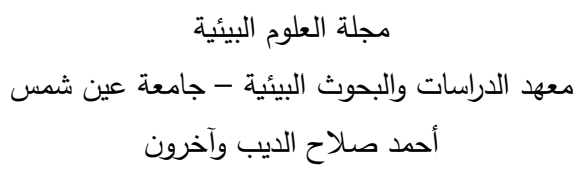

تابع جدول(؟): الوظيفة والفعالية لقسم العيادات الخارجية لمستثفي كفرالثيخ الجامعي.

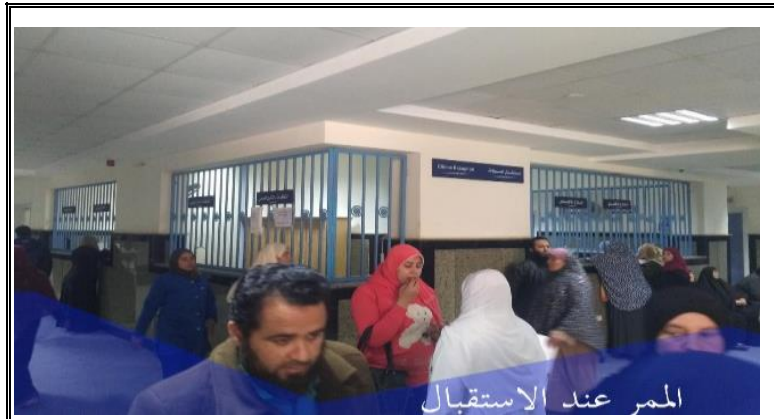

الطرقات والممرات: ليس لها شكل

منتظم يمكن تحديدها من خلالها لماته كذلك يوجد أماكن انتظار خلالها مما يؤدي الي تقاطع مسارات التطات الحركة سواء الّاخل أو الخارج منارج

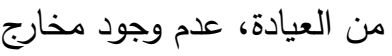

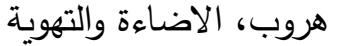

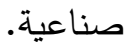

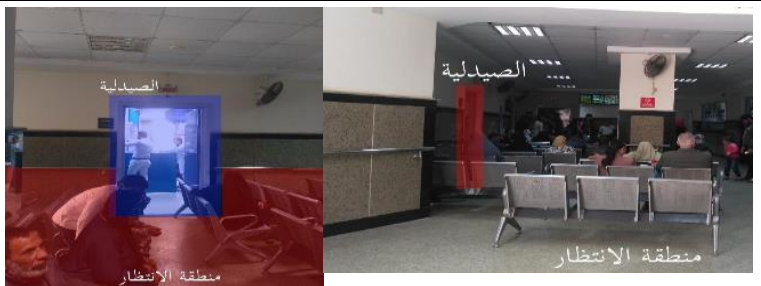

الصيدلية: بجوار منطقة الانتظار

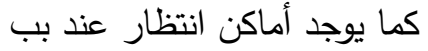
الصيدلية مما يؤثر علي حركة النطار عندة المرضي داخل منطقة الانتظار وعند دخول الصيدلية والخروج منها.

r. التنظيم المكاني والتكوين: المحدات الرأسية والأفقية للفراغات المتمثلة في الحوائط والأسقف والأرضيات والفتحات سواء أبواب وشبابيك وعناصر الفرش المستخدم سواء

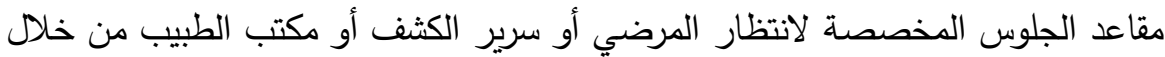
ذلك يمكن تقييم كفاءة التنظيم المستخدم ومكان كل عنصر .

فالتتظيم المكاني يؤثر علي رضا المستخدمين وسهولة وصولهم وتوفير بيئة ملائمة لمرافق، كذلك ملائمة الفراغات للتغيرات المستقبلية نتيجة الممارسات الجديدة والاكتشافات العلمية، الحد من سقوط المرضي والتعرض لمشاكل، ومكان محطة التمريض ( ZHAO

وبالقاء الضوء علي عناصر التشكيل والتتظيم المكاني لقسم العيادات شكل (T) نجد أن منطقة الانتظار غير محددة وبالتالي شكل مقاعد الانتظار الخاصة بالمرضي وطريقة تنظيمها داخل الفراغ غير جيدة، وتم تجميعها بشكل متوازي وملاصق للحائط، توزيع الفرش داخل

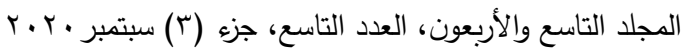




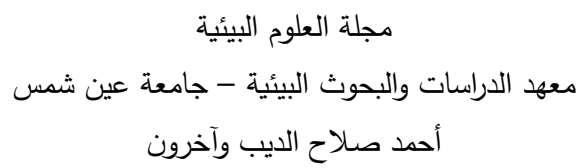

العيادات تم بطريقة تجعل الحركة داخل العيادة غير مرنة، وجود فاصل حديدي أعلي الكاونتر

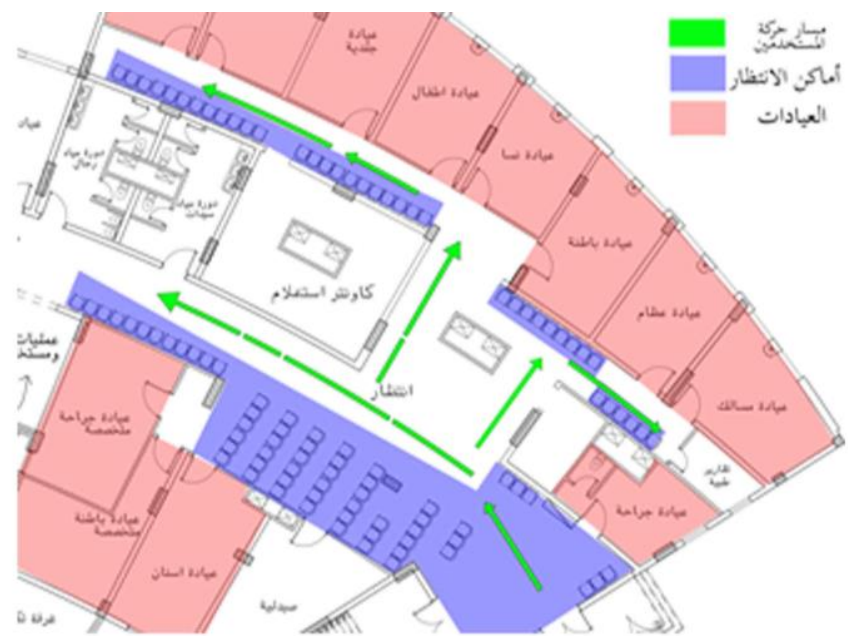

شكل(؟): التظيم المكاني للانتظار داخل قسم العيادات الخارجية - مستثفي كفرالثيخ

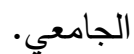

r. رضا المستخدمين: رضا المستخدمين داخل المبني يعتبر من أهم المؤشرات التي تعكس

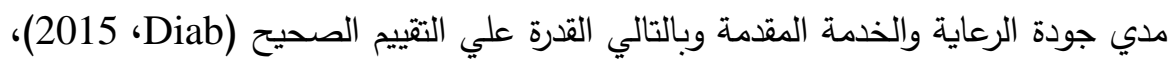

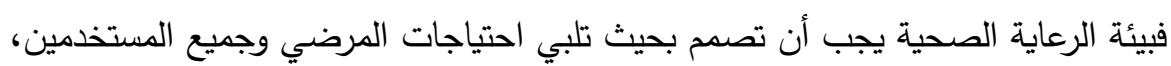

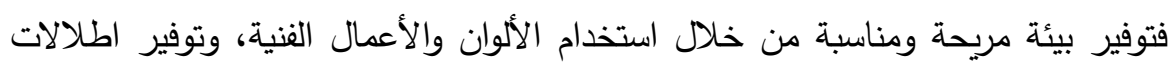
خارجية من خلال الفتحات ويفضل الاطلال نحو الطبيعة، الاضاءة الكافية الطبيعية، وتوفير المعلومات المطلوبة، أيضا توفير فراغات مناسبة يساعد في تهيئة البيئة الداخلية من حيث الهذوء والخصوصية والنظافة والثعور بالتحكم ووجود حمامات سهل الوصول

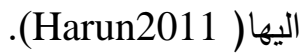

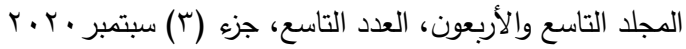

$$
\begin{aligned}
& \text { الترقيم الدولي 0826-1110 الارعون، }
\end{aligned}
$$


الألوان الفاتحة كالأزرق السماوي والأخضر الزاهي والأبيض أخف وزنا فتعطي انطباعا

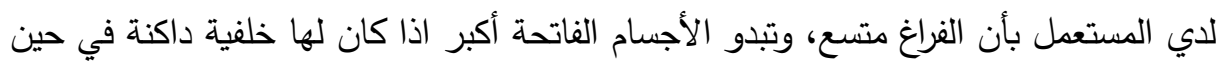

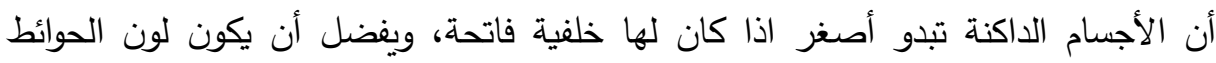

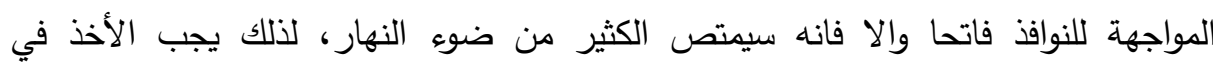
الاعتبار الأثر اللوني وتأثير الألوان المجاورة. لانهاه

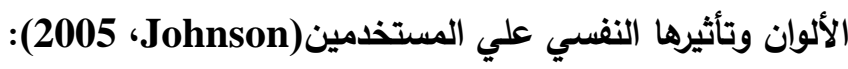

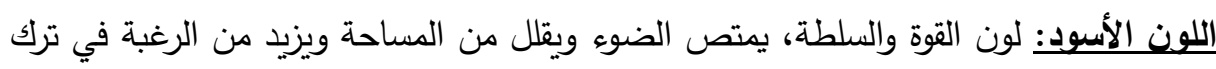
المكان. الللون الأبيض: يعكس الضوء ويجعل الفراغ أكثر نصاعة ويولد شعور بالراحة والسعادة بالوجود بالمكان. الللون الأحمر: يحرك المشاعر العاطفية لدي المستخدم، يعمل علي زيادة ضربات القلب

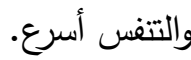
الللون الأزدق: عكس اللون الأحمر يعمل علي الاسترخاء والهدوء.

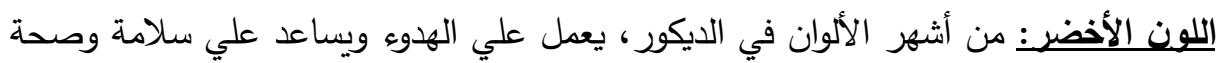
العين. الللون الأصفر: علي الرغم من كونه لونا مريحا الا انه يعمل علي الثعور بفقدان الطاقة كما

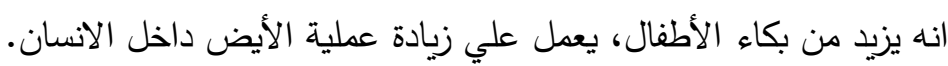

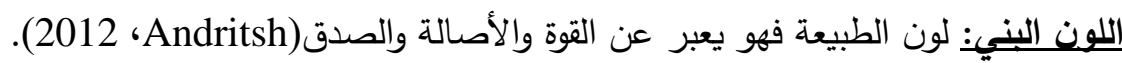

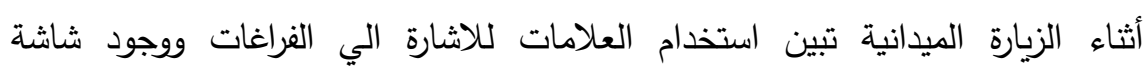

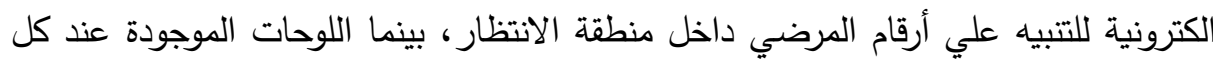

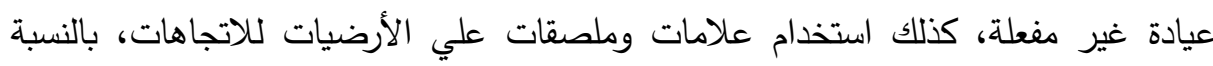
للألوان وجد أن الحوائط قد تم دهانها باللون البيج الفاتح في الجزء العلوي منها وتجليد الجزء 46

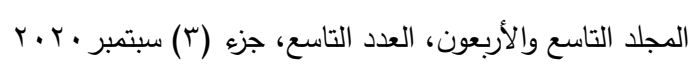

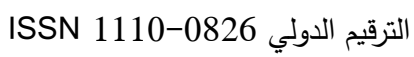


السفلي منها بجرانيت فردي غزال بدرجات البني والأسود دبل بلاك وكذلك الأرضيات وفي الأسقف تم استخدام أسقف معلقة باللون الأبيض.

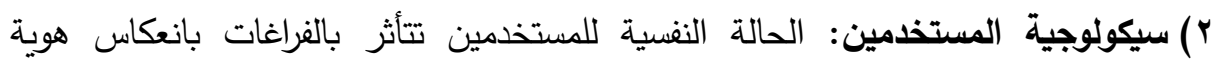
وطبيعة المكان شكل (^) حيث يوجد تفاعل بين المستخدمين والفراغ، فالفراغ يحدد باغنين المستخدمين ويحددونه، والحالة النفسية للمستخدمين وتفاعلهم تتأثر بالثقافة والدين والنوع ولثين

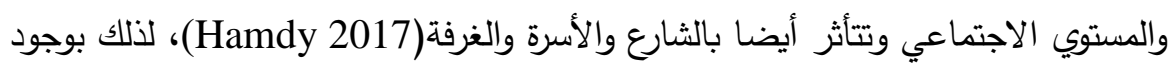
أكثر من مستخدم يكون لهم تفاعل كبير بينهم وبين المكان.

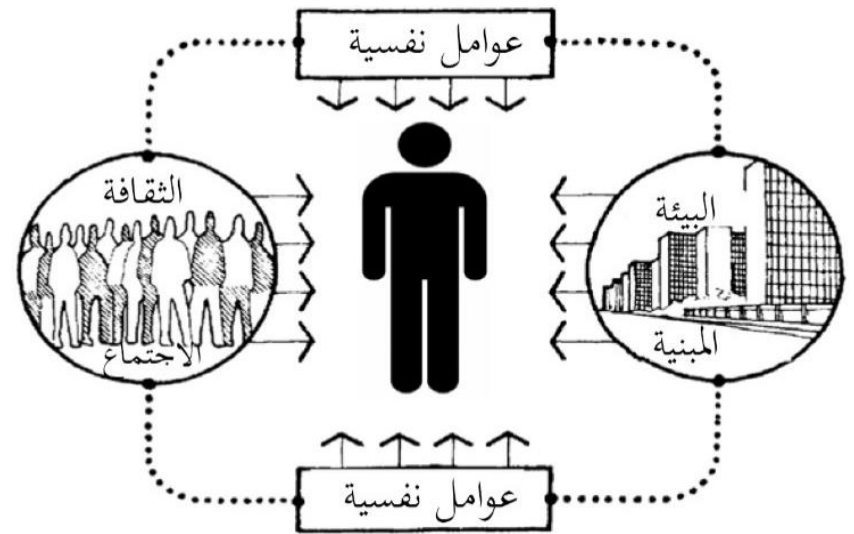

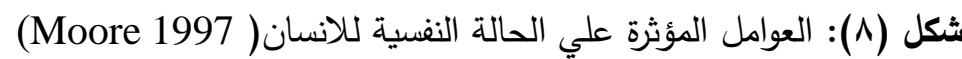

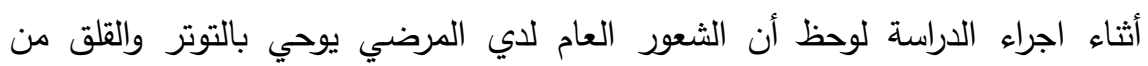

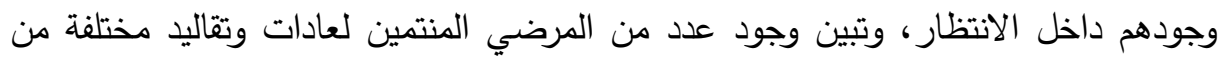

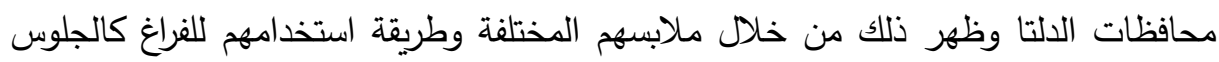
علي الأرض بدلا من اماكن الانتظار، كذلك كيفية اسغلال وقت الفراغ أثناء الانتظار سواء باستخدام المحمول أو الحديث مع الاخرين أو تتاول مشروبات سريعة أو الاهتمام بأولادهم أثناء الانتظار أو الانتظار فقط شكل (9) لذلك فانه يجب الحفاظ علي هوية المستخدمين

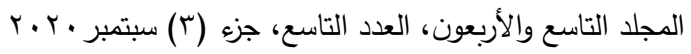

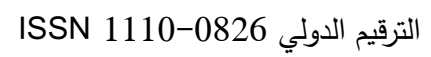




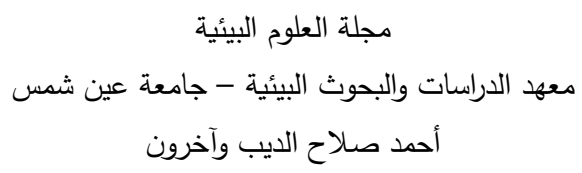

واحترام عاداتهم لتلبية احتياجاتهم مع الحفاظ عليها للاجيال القادمة، حيث ان المستخدمين

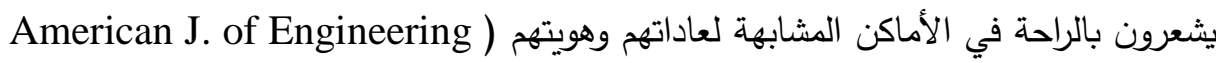
.(and Applied Sciences 2010
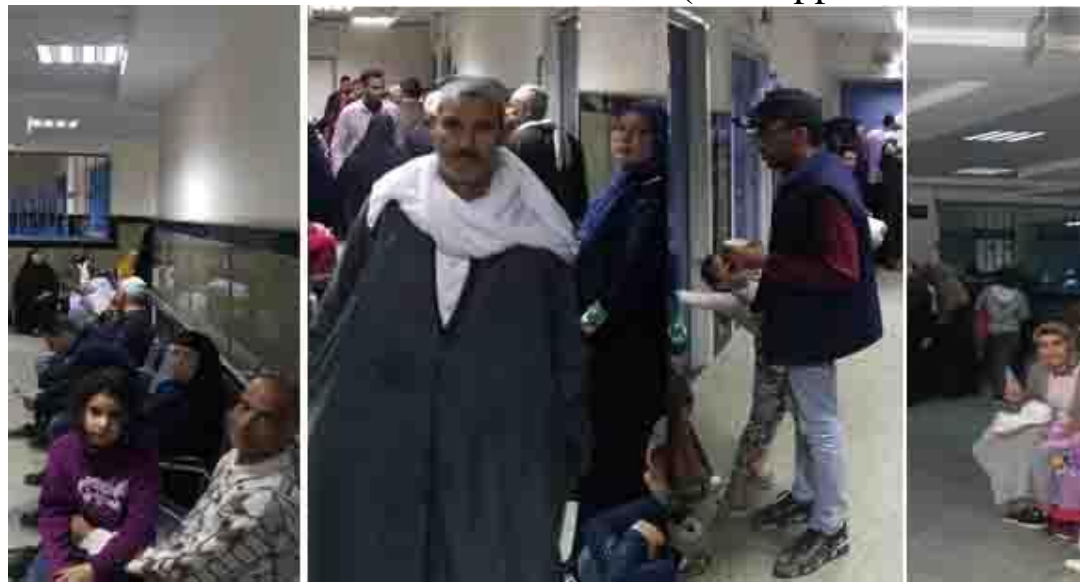

شكل(9): عادات وسلوكيات المرضي داخل منطقة الانتظار بقسم العيادات.

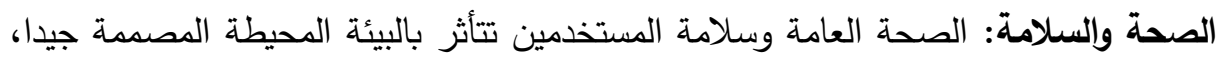
فالتصميم الذي يراعي احتياجات المستخدمين يستطيع أن يقلل ويحد من المشاكل الصحية بلهية

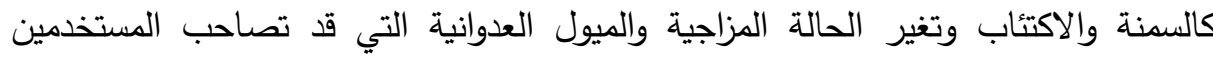
Commission on the Social Determinants ) نتيجة وجودهم في بيئة غير مناسب ولئه

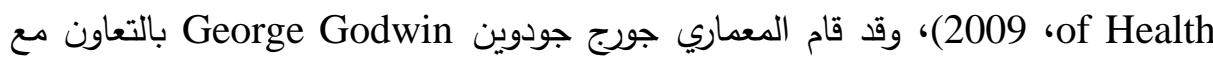
الممرضة فلورنس نايتجيل Florence Nightingale بتحويل التصميم المتعارف عليه للمستشفي في العصر الفيكتوري بهدف تحسين الصحة العامة وذلك من خلال الاعتماد علي الفتحات ذات الاتجاه الرأسي لاخول أكبر قدر من أشعة الثمس والتهوية الجيدة وايجاد التهاد

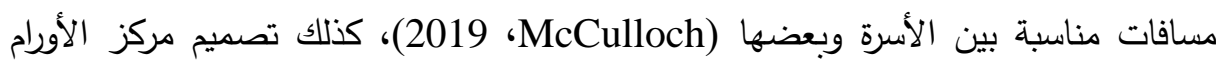
بمدينة نورفك الانجليزية اعتمد علي تحسين الصحة العامة من خلال استخدام "التصديم 48

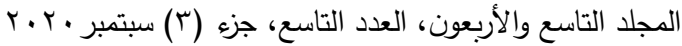

$$
\begin{aligned}
& \text { الترقيم الدولي 0826-1SSN 1110 }
\end{aligned}
$$


المنزلي" والذي يوحي بوجود المريض بمنزله حيث لا يوجد مكتب استقبال "كاونتر" وتم ايجاد

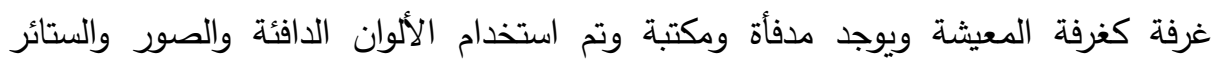

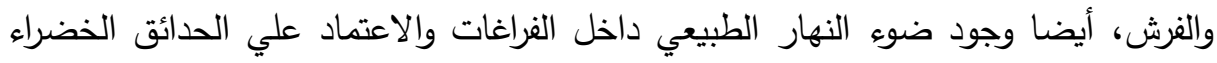

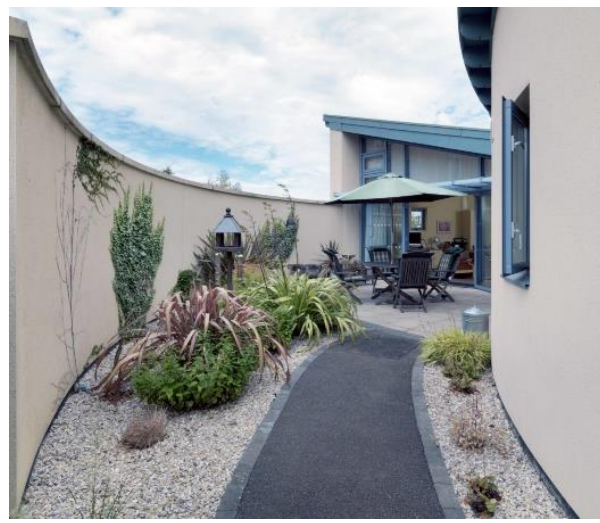

الداخلية شكل (• (1).

شكل(· King's ، 191 · ملي اليسار جناح الاقامة بمستثفي سانت توماسو كاليفورنيا، College Archives: St Ts ward بمركز الأورام بمدينة نورفك.

لذلك نجد أن المصمم لديه خيارات متعددة يستطيع من خلالها التحكم في صحة وسلامة نورفة المستخدمين وجعل التصميم متوائم مع ظروف البيئة المحيطة كالتهوية والاضاءة ودرجة الحرارة والرطوبة، كذلك المعرفة الجيدة بالمواد المستخدمة في التثطيب كالزجاج والدهان والأقمشة ومدي قوة تحمل الخامات للاحتكاك والانزلاق، كذلك معرفة المواد المسببة للتلوث

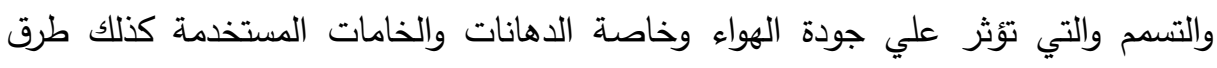
تطبيق المعايير والأكواد الملزمة لذلك تم تحديد مجموعة من العناصر التي يمكن من خلالها وداهيا قياس مدي الحفاظ علي صحة وسلامة المستخدمين:

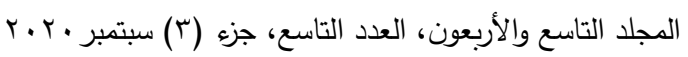

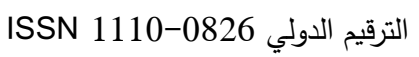




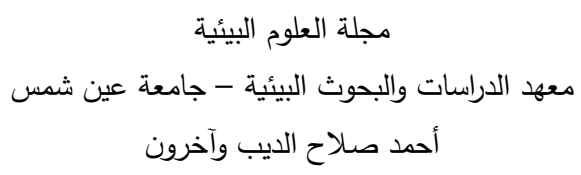

• الوصول الي الفراغات الداخلية بطريقة امنة وتوفير انتقال امن لذلك. •وجود علامات ولافتات واضحة ومرئية بحجم مناسب توضح الاتجاه الصحيح. •تجنب حدوث تغير مفاجئ في الحركة واذا حدث يكون ببعض العناصر كالألوان والعلامات. •الاعتماد علي خامات سهلة التتظيف وغير عاكسة في في الأرضيات. •استخدام أبواب ذات درجة متانة وقوة عالية.

•تحسين مستوي الاضاءة في الاماكن المحددة لذلك مع القدرة علي التحكم فيها. •الاعتماد علي عوامل الامن والأمان بكاميرات مراقبة ونظام اتصال من خلال غرفة الامن تحكم. • الاعتماد علي أثاث مريح وامن مع تصميم صحي.

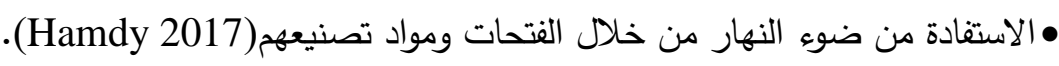
فالحركة داخل قسم العيادات الخارجية بمستثفي كفرالثيخ الجامعي نجد أنها غير منظمة بطريقة مريحة للمستخدمين، كذلك الاضاءة الطبيعية غير كافية في الانتار ولكنها مناسبة داخل العيادات، يوجد نظام اتصال داخلي وكاميرات مراقبة شكل (1') عروض السئ السلالم وارتفاعتها مناسبة واستخدام هاندريل للمرضي والمسنين، يوجد نظامين للاطفاء احدهما الي

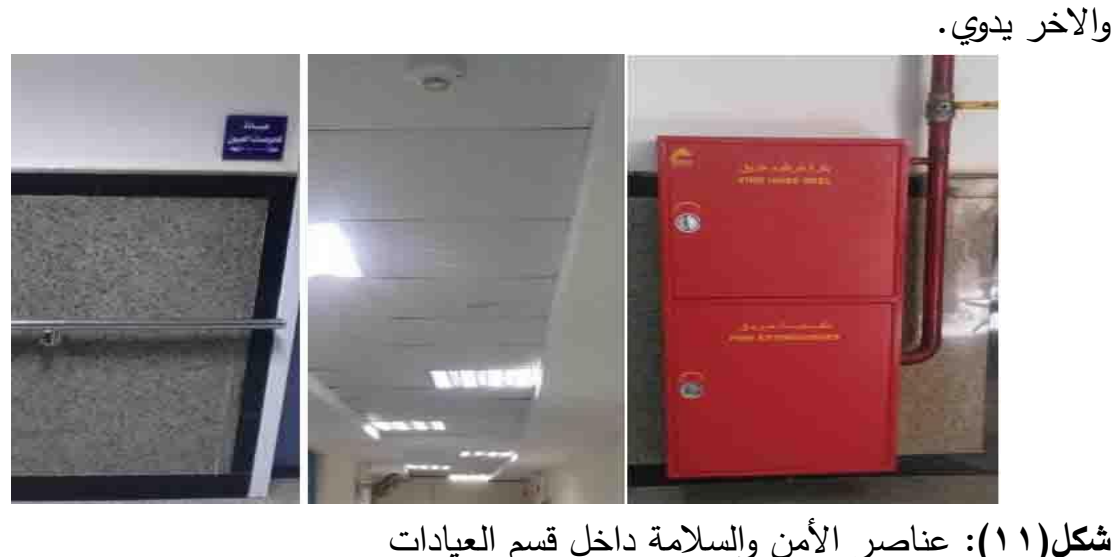




$$
\begin{aligned}
& \text { مجلة العلوم البيئية } \\
& \text { معهد الدراسات والبحوث البيئية - جامعة عين شمس لبنه } \\
& \text { أحمد صلاح الديب وآخرون }
\end{aligned}
$$

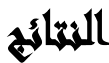

من خلال الجزء السابق من البحث والذي تتاول بعض من العناصر التي يمكن

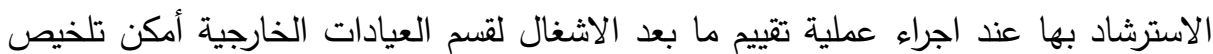

مجموعة من العناصر التالية شكل (r ( ).

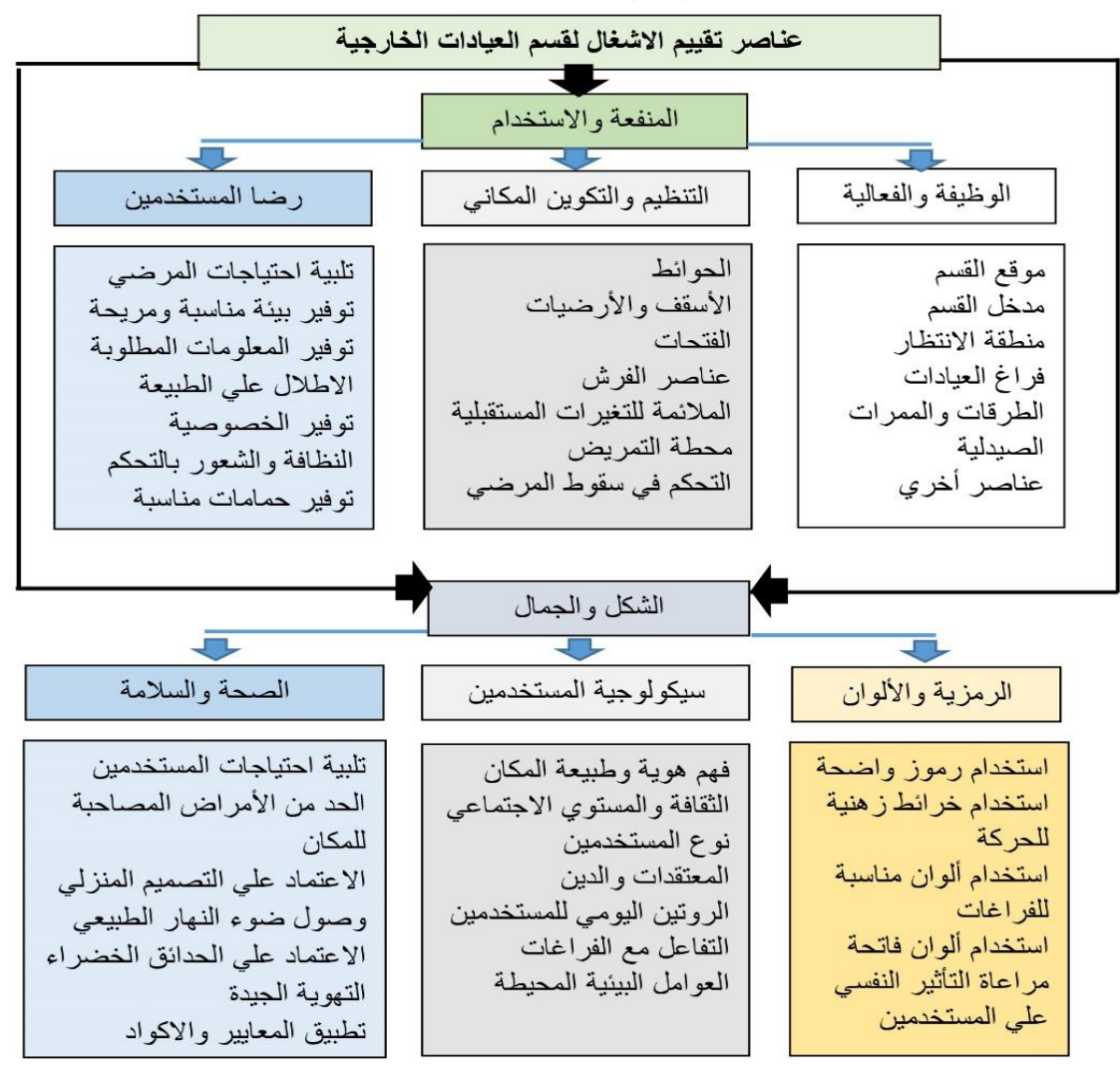

شكل(Y I): عناصر تقييم ما بعد الاشغال لقسم العيادات الخارجية ( الباحث)

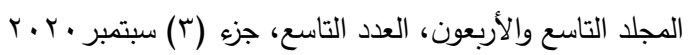

الترقيم الدولي 0826-1110 119 
مقترح تطوير العيادات الخارجية بمستشفي كفرالثيخ الجامعي طبقا لعناصر تقييم ما بعد الاثغال: تم عمل مقترح لتطوير قسم العيادات الخارجية استنادا الي عناصر التقييم التي تم الوصول اليها في الجزء السابق من البحث والتي جاءت شكل (ب ا) علي النحو التالي:

- الوظيفة والفعالية: اضافة أماكن انتظار خارجية أمام العيادات باستخدام المنطقة المفتوحة أمام القسم وتظليلها لتستوعب عدد أكثر ووصول النهار لها، استخدام أحد الشبابيك الموجودة بكل عيادة (يوجد شباكين) وتحويلة الي باب، تحديد شكل الممرات وازالة مقاعد الانتظار .

- التنظيم المكاني والتكوين: تحديد أماكن الفراغات ومحطة التمريض والتأكيد عليها وازالة الحديد الموجود أعلي الكاونتر مع عمل بعض التغيرات بالحوائط واضافة العناصر الجديدة.

- رضا المستخدمين: اختيار الألوان وبيئة هادئة، اضافة بعد الرسومات والأشكال علي

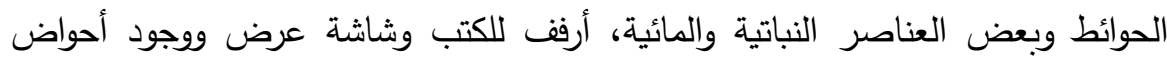
زهور وأسماك. - ماك.

- الرمزية والألوان: استخدام الألوان الفاتحة كالأزرق السماوي والأخضر الفاتح والبمبي لتعطي

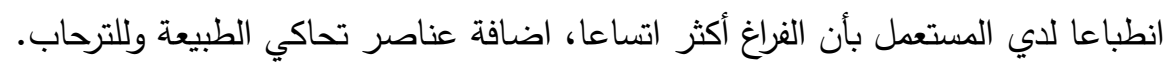

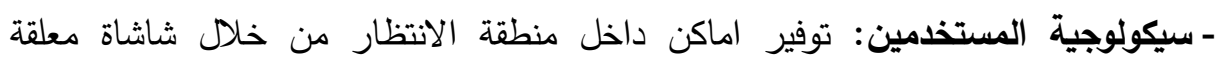

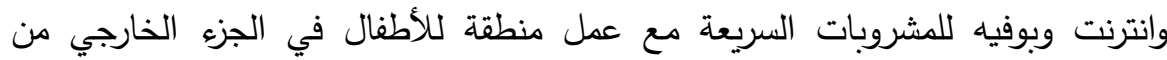




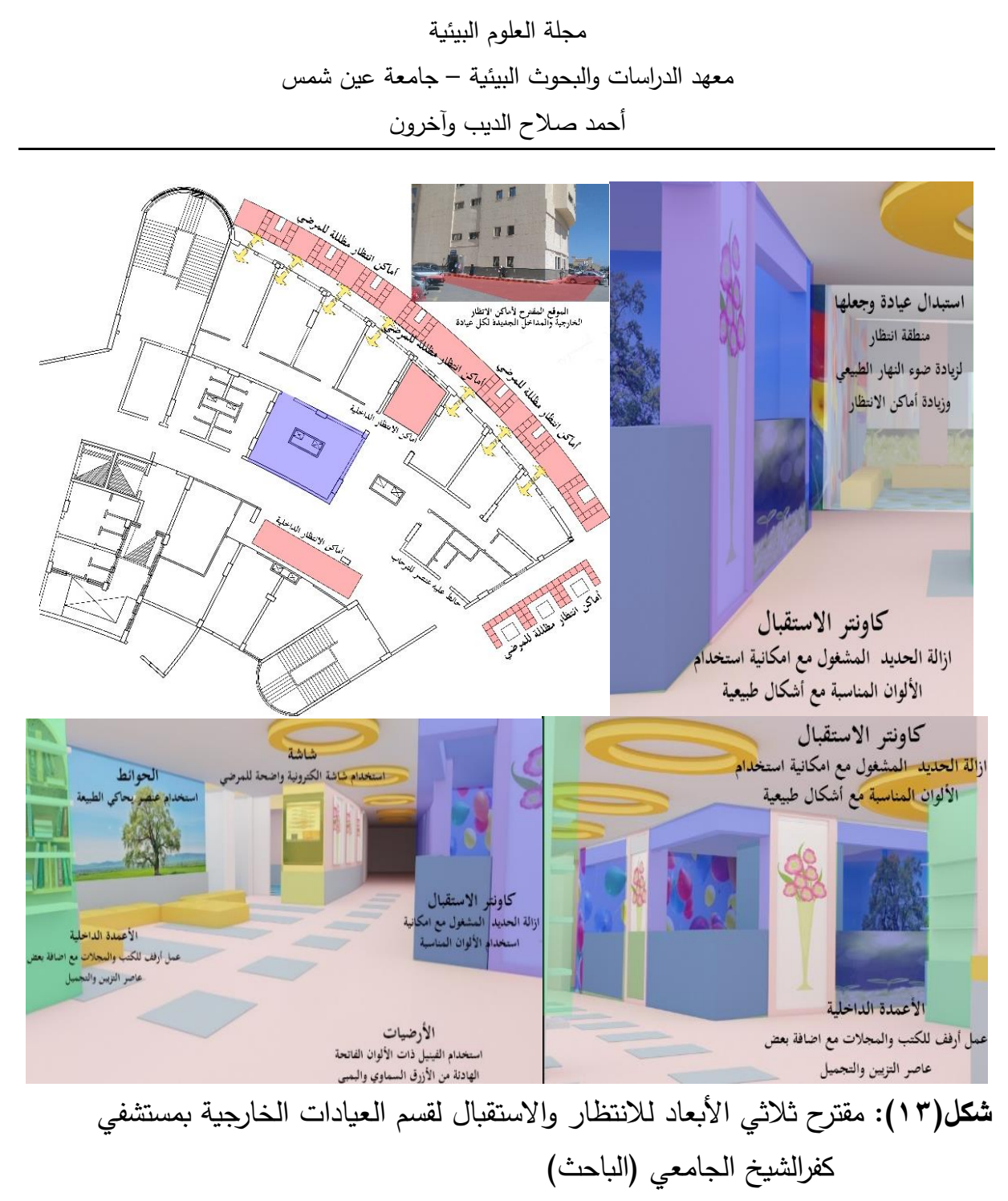

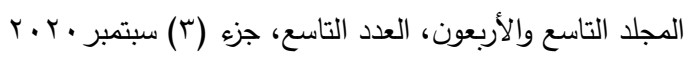

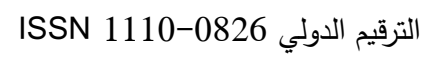



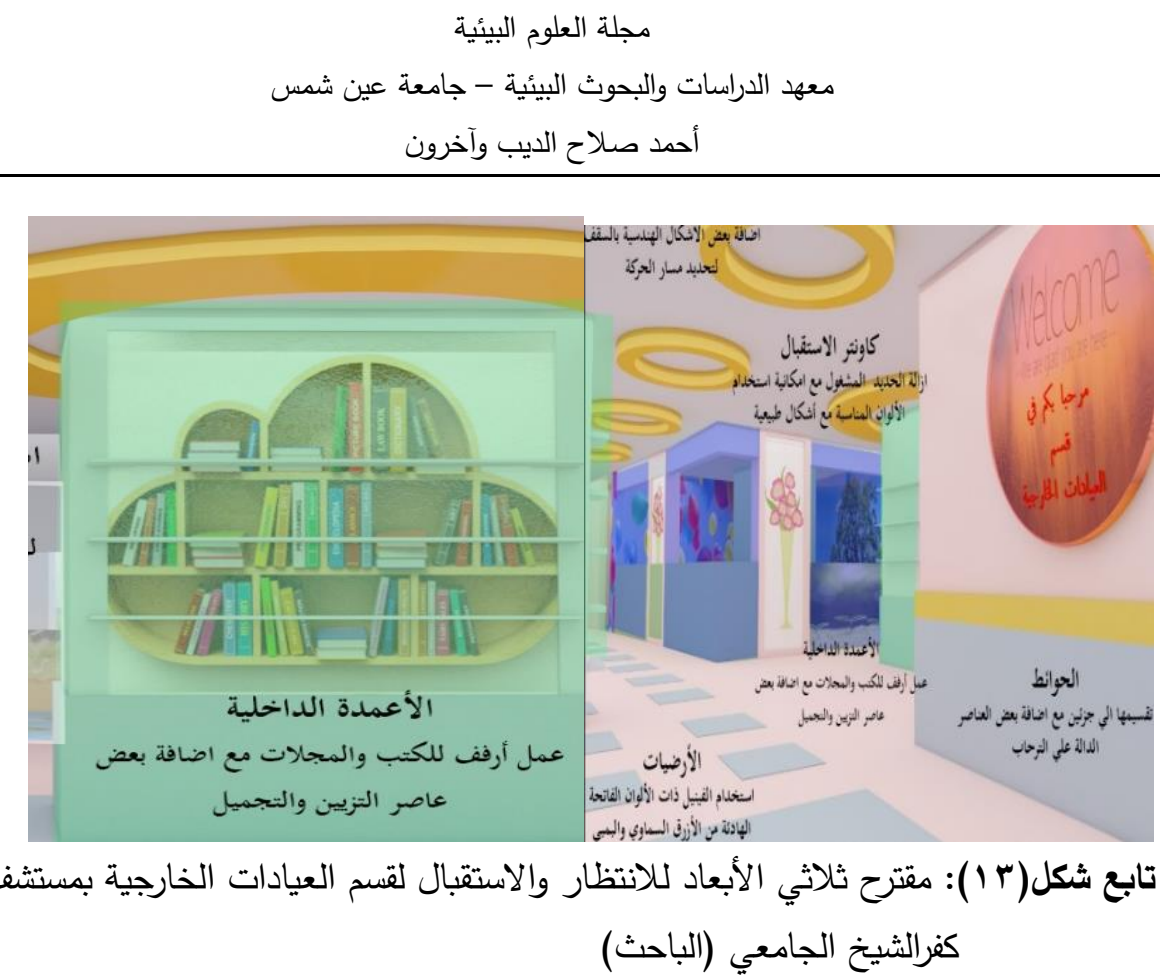

\section{اللزوكياني}

- الاستفادة من الورقة البحثية وعرضها علي ادارة المستشفي لاجراء التعديلات المقترحة والتي يمكن تطبيقها علي باقي الأقسام والتي تتشابه مع طبيعة قسم العيادات الخارجية. - تفعيل المقترح وعرضه علي الجهات المتخصصة وابداء رأيهم بناء علي الدراسات والتقاليد.

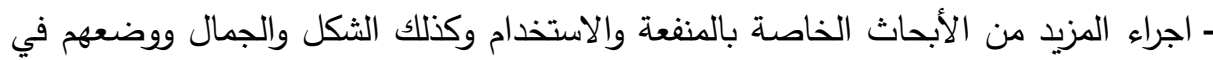

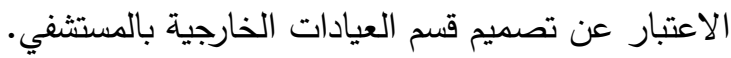
- الاستفادة من العناصر المقترحة لقسم العيادات في نطام تقييم اشغال المستثفيات. - البدء في انثاء نظام تقييم الاشغال الخاص بالمستثفيات المصرية وذلك بالتعاون مع مركز بحوث الاسكان والبناء ووزارة الصحة.

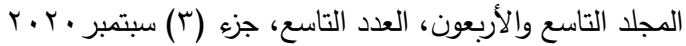

$$
\begin{aligned}
& \text { الترقيم الدولي 0826- ISSN 1110 }
\end{aligned}
$$




$$
\begin{aligned}
& \text { مجلة العلوم البيئية } \\
& \text { معهد الدراسات والبحوث البيئية - جامعة عين شمس لكس } \\
& \text { أحمد صلاح الديب وآخرون }
\end{aligned}
$$

$$
\begin{aligned}
& \text { - التوسع في دراسة المزيد من العناصر التي يمكن ادراجها ضمن نظام تقييم ما بعد الاشغال } \\
& \text { وذلك في اطار بحثي قائم علي الدراسات الميدانية لعدد من المستثفيات المصرية. }
\end{aligned}
$$

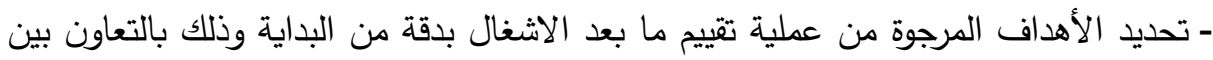

$$
\begin{aligned}
& \text { التخصصات المختلفة الموجودة بالمستثفي والمستخدمين حتي تقوم المستثفي بدورها. }
\end{aligned}
$$

\section{المراجية}

Sadek Ahmed H. aand Nofal Eslam M ،(2013): " Effects of Indoor Environmental Quality on Occupant Satisfaction in Healing Environments "Building Simulation Cairo- Towards Sustainable \& Green life ‘Conference.

American J. of Engineering and Applied Sciences (2010): "The Influence of Modernity on Kurdish Architectural Identity", $3(3) \cdot 554$

Ayalp ‘N.: "Cultural Identity and Place Identity in House Environment: Traditional Turkish House Interiors". Interior Architecture and environmental Design Department, TOBB ETU University, International Journal of Energy and Environment (2012) .

Huelat ‘B. J (2009): " The healing experience Healthcare" Architecture ، Healthcare Design Magazine 'pp.10-15.

Commission on the Social Determinants of Health '(2009): "Evidence from the Commission on Social Determinants of Health". Summary of Evidence for the Review of Health Inequalities Annex2.

Andritsch, E. and Stoeger, H, (2012): " The ethics of space 'design and color in an oncology ward" Palliative and Supportive Care Cambridge University Press 'Elsevier.

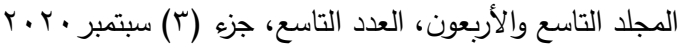

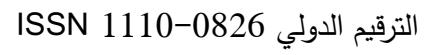




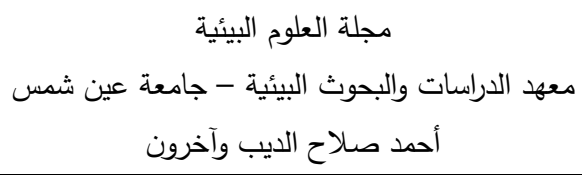

Fronczek-Munter, A: "Evaluation methods for hospital facilities", International Journal of Facilities Management, Technical University of Demark, (2013).

Fronczek-Munter, A. (2017): "Usability Briefing for hospital design: Exploring user needs and experiences toimprove complex buildings". Department of Management Engineering, Technical University of Denmark 'European healthcare design conference-London, 11-14 June 2017.

Haron, S.N and Hamid ‘M.Y,: "Quality of Hospital In-use: Usability Evaluation Method as Assessment" Journal of sustainable DevelopmentVol.4 No2, (2011).

Hay, R., Samuel, F., Watson, K. J. and Bradbury, S. (2017): "Post occupancy evaluation in architecture: experiences and perspectives from UK practice" 'Building Reserch \& Information ‘University of Reading.

Haytham S Diab,: "Assessment of patients' satisfaction in Ain Shams University Hospitals" Chest Department 'Faculty of Medicine, Ain Shams University, Cairo, Egypt, The Egyptian of Journal of Bronchology, (2015).

Heba-Talla Hamdy., (2017): " Interior Architectural Elements that Affect Human Psychology and Behavior" The International Conference: Cities' Identity Through Architecture and Arts ( CITAA), The Academic Research Community Publication.

Cowgill. Jamie, and JRC Design, SEGD ،(2010): "Universal Symbols for Healthcare", Society for Experiential Graphic Design, Washington ‘DC.

Kopacz Jeanne, (2004):" Color in Three-Dimensional Design" McGraw-Hill ‘New York ‘USA.

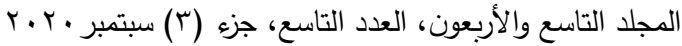

$$
\begin{aligned}
& \text { الترقيم الدولي 0826- ISSN 1110 }
\end{aligned}
$$




$$
\begin{aligned}
& \text { مجلة العلوم البيئية } \\
& \text { معهد الدراسات والبحوث البيئية - جامعة عين شمس لكس } \\
& \text { أحمد صلاح الديب وآخرون }
\end{aligned}
$$

McCulloch Jess, (2019): "Living with Buildings", wellcomecollection.org.

Johnson, D., (2005): " Psychology of Colors" https://www.infoplease.com/color-psychology.

Kalantari, S. (2016): "A digital pre-occupancy architectural toolset for reducing stress levels in urban environments". GSTF Journal of Engineering Technology (JET), 4 ،8-12.

Moore, G. (1997):."Architecture and Human Behavior: The Place of Environment-Behavior Studies in Architecture" (First ed.). Madison: Wisconsin Architect

Nicholas Watkins ‘Erin Peavey, and Derrek Clarke ‘(2012): " Research in Practice "Healthcare Design Magazine.

Preiser, W. F. E. and Vischer, J. (Ed.) (2005): "Assessing Building Performance" "Elsevier.

Preiser, W.F.E. and Rabinowitz ‘H.Z., and White ‘E.T. (2016): "PostOccupancy Evaluation". New York: Van Nostrand Reinhold ‘Routledge Revivals

S.N.Harun, M.Y.Hamid, ATalib, Z.A.Rahim., (2011): " Usability Evaluation: Criteria for Quality Architecture In-use "The 2nd International Building Control Conference 2011, Procedia Engineering.

The Centre for Health design ،(2015): "A Guide to Clinic Design PostOccupancy Evaluation Toolkit".

ZHAO, Y., MOURSHED, M., (2009): " Factors influencing the design of spatial layouts in healthcare buildings "Danity, A.R.J. (ed) Proceedings of the 25th annual ARCOM Conference ، Nottingham ،England.

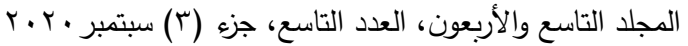

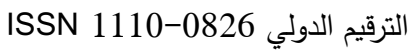




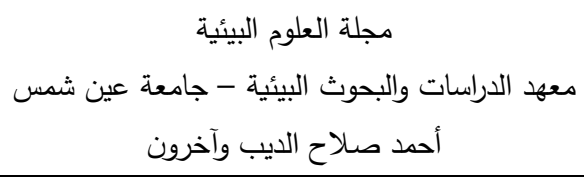

\title{
POST-OCCUPANCY EVALUATION FOR OUTPATIENT DEPARTMENT IN KAFR EL SHEIKH UNIVERSITY HOSPITAL.
}

\author{
Ahmed S. El-Deep ${ }^{(1)}$ and Dalia S. Said ${ }^{(2)}$ \\ 1) Lecturer, Architecture Department, faculty of Engineering, Kafr \\ Elsheikh University 2) Assoc.prof, Architecture Department, faculty of \\ Engineering, Kafr Elsheikh University.
}

\begin{abstract}
Methods of health care buildings Post- Occupancy are variable ، including the quality of the design 'the measurement of the service provided 'measuring their impact on the patients and the users 'or the management system. Post- Occupancy is evaluated through field visits ، observation and data collection from the users to the building The aim of the research is to try to understand the Outpatient department at Hospital of Kafr Al Sheikh University and the reactions of users during their time in the department and their impact on the elements of utility and use represented by the effectiveness of the architectural design of the department and the Spatial organization As well as user psychology and the health and safety of users by identifying a set of elements through which to measure the extent of preservation of the user. Health and safety of users on the other hand sthe research was based on data collection through the field visit to department and interview and dialogue with users such as patients and staff and engineering management in hospital.

The research found a number of elements of the assessment of works that can be included in the system of general occupancy evaluation of the hospital including a three-dimensional proposal to modify the department of outpatient clinic Kafr Al Sheikh University. 58

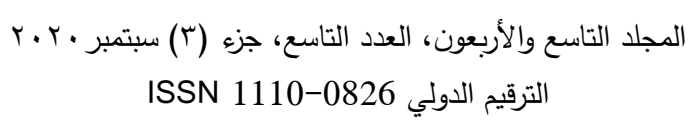

